\title{
Pre-hospital Care for Suspected Stroke Patients, Cared for by Mobile Emergency Care Units in Northern Minas Gerais
}

Lorenn Lages Gusmão, ${ }^{1 \oplus}$ Israel Junior Borges do Nascimento, ${ }^{\circledR}$ Gabriel Almeida Silqueira Rocha, ${ }^{\circledR}$ João Antonio de Queiroz Oliveira, ${ }^{\circledR}$ Geisiane Sousa Braga Machado, ${ }^{\circledR}$ Izabella de Oliveira Antunes, ${ }^{\circledR}$ Romeu Vale Sant'anna, ${ }^{\circledR}{ }^{\circledR}$ Breno Franco Silveira Fernandes, ${ }^{1}$ Ubiratam Lopes Correia, ${ }^{3}$ Antonio Luiz Pinho Ribeiro, ${ }^{(\circledR)}$ Milena S. Marcolino ${ }^{1}{ }^{\circledR}$

Hospital das Clínicas da Universidade Federal de Minas Gerais, ${ }^{1}$ Belo Horizonte, MG - Brazil

Hospital Risoleta Tolentino Neves, ${ }^{2}$ Belo Horizonte, MG - Brazil

Núcleo de Educação Permanente (NEP) do SAMU, ${ }^{3}$ Montes Claros, MG - Brazil.

\section{Abstract}

Background: Stroke management require rapid identification, assessment, and transport of patients to qualified health care centers. However, there is little description in the literature on the multiple challenges associated with the pre-hospital transport of suspected stroke patients.

Objective: To characterize the pre-hospital care provided to suspected stroke patients by the Brazilian Emergency Medical Service (SAMU in Portuguese), by means of a descriptive case study.

Methods: This is a descriptive study of a series of cases. Data from the SAMU regarding the responses to emergency calls from suspected stroke patients were collected. Independent reviewers confirmed the diagnostic hypothesis and all discordances were assessed using kappa statistics. Clinical data and transport times were described as frequency and proportion or central tendency and dispersion measures. Normality of continuous variable distribution was assessed using the Kolmogorov-Smirnov test. The Mann-Whitney U test was used for comparison of medians, with a $5 \%$ significance level.

Results: During the studied period, 556 suspected stroke patients were treated. The kappa index was 0.82 (95\% CI 0.737 to 0.919 ) CI. In $74.7 \%$ of the cases, the symptom onset time was not recorded. The median time elapsed between the call for emergency services and the ambulance arrival was 18 minutes, and the median transport time was 38 minutes. A total of $34 \%$ of the patients were taken to referral hospitals for stroke.

Conclusion: This study revealed a low level of knowledge regarding the need to determine the exact time of symptom onset of suspected stroke patients. Also, the study showed the low rate of patients taken to referral hospitals. (Int J Cardiovasc Sci. 2021; 34(3):245-252)

Keywods: Epidemiology; Stroke; Preventive Health Services; Health Programs and Plans; Public Health; Health Policy.

\section{Introduction}

Strokes are one of the main causes of morbidity and mortality, functional disability, work absenteeism, and social-economic insecurity in Brazil and worldwide. ${ }^{1}$ According to data provided by the World Stroke Organization (WSO), one in every six individuals in the world will have at least one stroke episode. ${ }^{2}$ Another very relevant aspect is the monetary cost to public and private sectors related to stroke patients. An American study published by the Center for Disease Control (CDC) estimated that 34 billion dollars are spent annually on stroke-related expenses, including hospital stay, professional care team, pharmacotherapy, and indirect losses. ${ }^{3}$ A recent study conducted at the Federal University of Goias estimated that the average national cost of hospital care of stroke patients has exceeded 1.5 billion Brazilian reals. ${ }^{4}$ Thus, the clinical, epidemiological, 
economic, and social impact of stroke triggers the need for studies on this topic in Brazil.

Due to its severity and epidemiological importance, stroke was included by the American Heart Association in the basic and advanced life support algorithms, requiring proper and specialized training in referral care centers. ${ }^{5}$ Similarly, the Brazilian Department of Health created the "Line of Stroke Care" and defined it as a priority. ${ }^{6,7} \mathrm{It}$ refers to a dynamic, multidisciplinary monitoring system focused on rehabilitation, education, and care for patients and their caretakers, starting from hospital discharge, and on handling of expected clinical outcomes. ${ }^{8}$ In 2008, the General Coordination of Urgency and Emergency of the Ministry of Health created a national stroke network, by means of the National Stroke Project, to include all levels of health care in the task force against stroke, thereby raising the public's awareness, pre-hospital care, hospital care, rehabilitation, and prevention. ${ }^{9}$

A key factor in the prognosis of stroke patients is the time elapsed between symptom onset and treatment. It is recommended the administration of thrombolytic drugs within three hours of symptom onset (with the possibility of extending up to four and a half hours in selected cases), and performance of thrombectomy procedures up to 24 hours after symptom onset, i.e., during the hyperacute phase of stroke. In this sense, the pre-hospital care service plays a critical role in the prognosis of stroke patients, including an effective transport, symptom recognition and/or initial management of patients. ${ }^{10}$ A study conducted in San Francisco involving trained paramedics, who participated in a training program designed to improve the recognition of stroke symptoms, and untrained paramedics, revealed that, after the program had been implemented, there was a significant increase in the identification of acute stroke patients. ${ }^{11}$ Therefore, the creation of continued training programs for health care workers, especially pre-hospital care teams, is essential for the early detection of stroke cases and subsequent referral to specialized units. In Brazil, the Mobile Emergency Care Service (SAMU) has become key element in identifying suspected stroke, monitoring patients' vital functions, quick transport of patients to the appropriate care unit, and notifying this facility where the stroke patient will be admitted. ${ }^{12}$

\section{Extended North Minas Gerais Region}

Minas Gerais is the fourth largest state in Brazil by area $\left(586,528 \mathrm{~km}^{2}\right)$ and the second in population, with
$19,597,330$ inhabitants ( $10 \%$ of the Brazilian population) according to the last census (2010) conducted in the country. ${ }^{13}$ Between January 2013 and June 2014, a total of 29,145 hospital admissions for stroke was registered in the state. ${ }^{14}$ According to data from DATASUS database, the mortality rate due to cerebrovascular diseases is 52.3 per 100,000 inhabitants in Brazil, and of 51.8 per 100,000 inhabitants in Minas Gerais, which stands in the ninth position in the ranking position with the highest mortality rate from cerebrovascular diseases in Brazil. ${ }^{14}$

The state of Minas Gerais is divided into 12 macroregions; the north region is the largest one, with a territory corresponding to that of the states of Santa Catarina and Alagoas combined, distances between cities of up to 500 kilometers, and extensive rural areas. ${ }^{13}$ It includes 89 municipalities, with significant social inequality and low demographic density. ${ }^{13}$ A study conducted by the Pan American Health Organization/WHO, in partnership with the Brazilian Department of Health and the Minas Gerais Department of Health, identified a higher risk of premature death from chronic degenerative diseases in Jequitinhonha and Northern Minas Gerais. ${ }^{15}$ Among all the stroke cases registered in the state of Minas Gerais, 2,724 cases occurred in this region. ${ }^{14}$

The Inter-municipal Health Consortium of the Urgent Care Network of Northern Minas Gerais (CISRUN in Portuguese), integrates 86 of the 89 cities of the state, comprising approximately 1.6 million inhabitants. This service is based on 48 mobile units, of which 41 are basic health units (USB in Portuguese), in which patients are seen by two nurse technicians, and seven are advanced health care units (USA in Portuguese), consisting of a physician, a nurse, and a driver. These mobile units provide pre-hospital care over the region and make patient transport to the referral hospitals easier. Considering the important role played by the CISRUN in Northern Minas Gerais, as well as the epidemiological, clinical, and socialeconomic relevance of stroke, this study was designed to characterize the pre-hospital care provided by SAMU to suspected stroke patients in Northern Minas Gerais.

\section{Methods}

This is a descriptive study of a series of cases of suspected stroke patients provided by the SAMU of Northern Minas Gerais. Data were collected from the SAMU Registration Center, located in the area's main city, Montes Claros, by two trained researchers, from March to December 2014. 
Cases of suspected stroke was identified by two independent reviewers (R.S. and B.X., experienced neurologists). In case of disagreement, an additional review was performed by the study coordinator (M.S.). Among suspected stroke patients, patients were classified by SAMU as emergency care (pre-hospital), therefore excluding patients associated with interhospital transport. The assessment included: (i) patient identification; (ii) date and time of symptom onset, SAMU call, SAMU ambulance arrival at the event location, SAMU ambulance departure from the event location, and SAMU ambulance arrival to its destination; (iii) code at departure: green, yellow, or red, which determine the event response priority as minimum, intermediate, or maximum, respectively; ${ }^{16}$ (iv) activation motivation; (v) Glasgow coma scale; ${ }^{17}$ (vi) Cincinnati pre-hospital stroke scale; ${ }^{18}$ (vii) vital data; (viii) procedures conducted in the ambulance; (ix) development and/or complications; (x) diagnostic hypothesis; (xi) destination and current status.

For analysis of care profile, the following were calculated:

i) travel time to respond: refers to the time elapsed between call for ambulance and its arrival to the event location;

ii) patient travel time: time elapsed between ambulance departure from the event location and its arrival to destination (hospital facility), except for the cases in which a referral hospital was not informed (a time equal to zero was defined in these cases); and

iii) total response time: time elapsed between the call for an ambulance and its arrival at the destination (hospital facility), including the travel time for assistance, time spent at the event scene, and patient travel time.

Regarding the destination hospital, the authors observed if suspected stroke patients were transported to the local referral hospital listed in the Brazilian Stroke Network - Irmandade Nossa Senhora das Mercês Santa Casa, located in Montes Claros. ${ }^{19}$

This study was approved by the Research Ethics Committee of the Federal University of Minas Gerais (UFMG) in 2011 (approval number 065/11).

\section{Statistical analysis}

Normality of continuous variable distribution was tested with the Kolmogorov-Smirnov test. Since the distribution was not normal, the median was used as measure of central tendency, and the interquartile range as measure of dispersion. Categorical variables were described by absolute and relative frequencies. The Mann-Whitney $U$ test was used for comparisons of the medians. The significance level for all tests was $5 \%$. All analyses were performed using the IBM SPSS Statistics software for Windows, version 21.0 (Armonk, NY: IBM Corp.).

\section{Results}

During the study period, 556 consecutive suspected stroke patients were treated by the SAMU of northern Minas Gerais. Among them, 299 patients received prehospital care and comprise the study sample. Median patient age was 70 years old (interquartile range [IR] 60-81 years of age, varying between 19 and 101), and 51.2\% of the patients were male. Regarding the motivation for the emergency call, the most frequent was motor impairment (54.8\%), followed by speech impairment (42.1\%) and facial asymmetry (33.1\%) (Table 1).

In $74.7 \%$ of the cases, patients or family members were unable to define the time of symptom onset, and $8.7 \%$ called the emergency service after four hours of the symptom onset. For only $72.9 \%$ of the cases, the emergency call was assigned a red code, which denoted maximum priority in pre-hospital care. Results of the Cincinnati and Glasgow scales are provided in Table 1.

Median "travel time to respond" was 18 (14.033.0) minutes and median "patient travel time" was 12 (IR 6.0-23.5) minutes. Median "total response time" was 57 (IR 45.5-91.0) minutes (Table 2). There was no statistically significant difference in "travel time to respond" between the north macro-region and Montes Claros micro-regions. Table 2 reveals greater "patient travel time" and "total response time" for the calls originating from Montes Claros macro-region ( $\mathrm{p}<0.01)$. Most patients (86.3\%) received hospital care within four hours of the call.

Most treated patients were referred (99.0\%) to hospital care; 110 patients were taken to the referral hospital for stroke care located in the respective macro-region, 22 were referred to other hospitals in Montes Claros, and 167 were referred to other health facilities in other cities. Among the patients who were not referred to hospital care, one was discharged at the event location, and two refused to receive treatment.

There was a high level of agreement between neurologists (1 and 2) in identifying suspected stroke $($ kappa $=0.82 ; 95 \%$ CI $[0.737 ; 0.919])$ (Table 3). 
Table 1 - Characterization of the sample treated by the SAMU of northern Minas Gerais (Minas Gerais, Brazil) regarding the pre-hospital care - motivation for the emergency call, time elapsed between symptom onset and service engagement, and clinical classification defined by the medical team $(n=299)$

\begin{tabular}{|c|c|}
\hline Characteristics & n (\%) \\
\hline Age, years & $70(60-81)$ \\
\hline Male & $153(51.2)$ \\
\hline \multicolumn{2}{|l|}{ Motivation for the call } \\
\hline Motor impairment & $164(54.8)$ \\
\hline Speech impairment & $126(42.1)$ \\
\hline Facial asymmetry & $99(33.1)$ \\
\hline Visual impairment & $6(2.0)$ \\
\hline Headache & $14(4.7)$ \\
\hline Other neurological symptoms & $11(3.7)$ \\
\hline Suspected stroke & $83(27.8)$ \\
\hline Hemiparesis/hemiplegia & $43(14.4)$ \\
\hline Lowered sensitivity & $45(15.1)$ \\
\hline High blood pressure & $13(4.3)$ \\
\hline \multicolumn{2}{|c|}{ Time elapsed between the symptom and the call to the emergency service } \\
\hline Less than 4 hours & $45(15.0)$ \\
\hline More than 4 hours & $26(8.7)$ \\
\hline Not informed/Unknown & $228(76.3)$ \\
\hline \multicolumn{2}{|l|}{ Activation code } \\
\hline Green (low risk) & $1(0.3)$ \\
\hline Yellow (intermediate risk) & $73(24.4)$ \\
\hline Red (high risk) & $218(72.9)$ \\
\hline Not informed & $7(2.3)$ \\
\hline \multicolumn{2}{|l|}{ Cincinnati scale } \\
\hline Informed & $66(22.1)$ \\
\hline \multicolumn{2}{|l|}{ Glasgow scale } \\
\hline Informed & $291(97.3)$ \\
\hline
\end{tabular}

\section{Discussion}

This study evaluated the profile of suspected stroke patients and of pre-hospital emergency care provided by the SAMU of north Minas Gerais in a large area that lacks sufficient health care resources. The results showed that stroke remains a disease associated with lack of knowledge by the residents in the area, given that only $23.7 \%$ of the people were able to tell exactly the symptom onset time, and, among them, a little over half called SAMU within four hours of the symptom onset.

For the vast majority of patients, the total service time took place within the four hours. However, due to inexact reports on the time of symptom onset, the fact does not ensure the treatment was provided within the 
Table 2 - Emergency response times of the pre-hospital care team

\begin{tabular}{|c|c|c|c|c|}
\hline Time elapsed (min) & $\begin{array}{l}\text { Total }^{*} \\
(\mathrm{n}=299)\end{array}$ & $\begin{array}{l}\text { From towns to } \\
\text { Montes Claros* } \\
\qquad(\mathrm{n}=170)\end{array}$ & $\begin{array}{l}\text { Outside Montes } \\
\text { Claros* } \\
(\mathrm{n}=129)\end{array}$ & p-value \\
\hline Travel time to respond + & $\begin{array}{c}18 \\
(14.0-33.0)\end{array}$ & $\begin{array}{c}19 \\
(15.0-30.0)\end{array}$ & $\begin{array}{c}17.5 \\
(13.0-43.0)\end{array}$ & 0.174 \\
\hline Patient travel time $\ddagger$ & $\begin{array}{c}12 \\
(6.0-23.5)\end{array}$ & $\begin{array}{c}13 \\
(9.0-20.0)\end{array}$ & $\begin{array}{c}11 \\
(5.0-31.0)\end{array}$ & 0.008 \\
\hline Total response time§ & $\begin{array}{c}57 \\
(45.5-91.0)\end{array}$ & $\begin{array}{c}61 \\
(49.0-78.0)\end{array}$ & $\begin{array}{c}53 \\
(40.5-118.0)\end{array}$ & 0.004 \\
\hline \multicolumn{5}{|c|}{$\begin{array}{l}\text { Comparison from towns to Montes Claros vs Outside Montes Claros (Mann-Whitney U test) } \\
\text { *Values expressed as median (interquartile range) } \\
+ \text { Time between the call for the ambulance and its arrival to the destination } \\
\text { ¥Time between the ambulance departure from the event location and arrival to the destination. For those cases where patients were not taken to any } \\
\text { referral hospital, the time was zero. } \\
\text { § Time between the call to emergency and arrival of patient to the destination }\end{array}$} \\
\hline
\end{tabular}

\begin{tabular}{|c|c|c|c|}
\hline \multirow{2}{*}{ Classification } & \multicolumn{2}{|c|}{ Neurologist 1} & \multirow[b]{2}{*}{ Total } \\
\hline & Included & Excluded & \\
\hline \multicolumn{4}{|l|}{ Neurologist 2} \\
\hline Included & 556 & 9 & 565 \\
\hline Excluded & 4 & 34 & 38 \\
\hline Total & 560 & 43 & 603 \\
\hline
\end{tabular}

period recommended by international guidelines. In addition, most patients were not referred to a referral hospital for stroke care, following the Brazilian Department of Health guidelines.

As described in clinical and observation studies, most patients with suspected or confirmed stroke are admitted to emergency health care units within three hours of the symptom onset. ${ }^{20}$ This fact may be related to the lack of knowledge about this condition, symptom onset during nighttime, patients living alone, among others. ${ }^{21}$ A study conducted in the city of Belo Horizonte in 2018 detected that only $56.1 \%$ of participants were able to recognize signs of stroke in a pre-selected video. ${ }^{22}$ In the north of Minas Gerais, considering the residents' low level of formal education, and the high poverty level, the lack of knowledge is probably even greater. ${ }^{23}$
In the aforementioned study, only 17 individuals $(2.4 \%)$ knew about the use of thrombolytic drugs for treatment of acute stroke. ${ }^{22}$

Results also indicated a possible failure of SAMU to recognize emergency situations for many of the patients assisted. Among the 299 patients treated for suspected stroke in pre-hospital care, only $72.9 \%$ were assigned a red code, that is, maximum priority in treatment and transport. Considering that the exogenous administration of thrombolytics and the patient's prognosis depend on the time elapsed between symptom onset and the arrival at the hospital, this study observed that such variables might have affected the outcome of these patients. In April 2017, the Stroke System of the macro-region of north Minas Gerais was launched in the city of Montes Claros, to improve care provided to stroke patients, 
reduce the average hospital stay for each patient, and to provide training and qualification for health care professionals, among others. Nevertheless, given that this implementation took place quite recently, it may be noted that descriptions of the results generated by such implementation are still scarce. ${ }^{24}$

The data provided reveal the importance of further discussing the establishment of priority at the SAMU system, prior to implementing a care line, as well as raising awareness and providing systematic qualification for the team. A study conducted in San Francisco compared awareness in recognizing acute stroke between trained and untrained paramedics before and after training. After training, a significant increase in sensitivity was detected among paramedics who had not been trained before. ${ }^{11}$

It is also important to emphasize the poor ability of the pre-hospital care team to recognize acute stroke and use the Cincinnati scale. Although its application is recommended by the Health Department and by the AHA in pre-hospital care, it has been reported that this scale was applied to only one in every 4.5 patients treated by SAMU. Its application is simple and for the detection of focal neurological deficits in the three parameters evaluated by this tool: motor skill, speech, and facial asymmetry. Despite recommendations, the use of the scale notified in only $20.2 \%$ of the responses, which can make the screening for stroke cases more difficult. Stroke sensitivity and specificity increase in direct proportion to the presence of these neurological alterations, making diagnosis and referral to specialized care units, and, therefore, early treatment, easier.

Regarding transport, despite the adversities that characterize the region - bad roads, long distances, river crossing on barges, and the interception of ambulances - the median transport time was adequate. However, some travels reached an extremely long time, possibly affecting patients' prognosis. The implementation of the stroke care line, with the use of telemedicine to make up for the insufficient number of neurologists in the area would be essential to enable a prompt response. ${ }^{25}$ However, the consolidation of positive trajectories associated with telemedicine requires the creation of hubs with access to computed tomography scanners and the possibility of prescribing thrombolytics remotely. Therefore, the benefits of telemedicine are multiple and pertinent to the holistic care for stroke patients. Telemedicine- directed stroke care provides remote medical services (especially from neurologists and remote consultancy for the admitted cases), involving rural and remote areas, where financial resources are scarce. ${ }^{26,27}$ Therefore, integration and articulation between mobile emergency care systems on the one hand, and reference hospitals for stroke care and telemedicine hubs on the other, are critical in achieving better results and prognosis associated with stroke cases. ${ }^{28}$

Another important aspect, in addition to an appropriate travel time, is the fact that the administration of thrombolytics is affected by the lack of precision in describing symptom development time. Thrombolysis is only indicated after four and a half hours after the onset of stroke symptoms and, in ischemic cases, there are systemic contraindications. ${ }^{16}$ In our study, only $25.3 \%$ of the patients could report the exact time of symptom onset. This may be due to the occurrence of stroke during sleep and manifestation of symptoms on awakening (wake-up stroke), and to the fact that individuals and their social circle may not notice symptom onset, as they believe that such manifestations are temporary. In addition, among those patients who were aware of their symptoms, only $20.7 \%$ called the emergency ambulance service within four hours of symptom onset. Considering this time (from symptom onset to ambulance call) and the travel time of 38 minutes, treatment with thrombolytics would be contraindicated for most patients. The importance of raising residents' awareness, taking into account their sociocultural competencies becomes more evident, to ensure the identification of symptoms as early as possible. In addition, according to Brazilian data, a specialized and quick response increases the chances of a good prognosis and less sequelae. ${ }^{29}$

Some problematic aspects are observed when obstacles related to responding to and understanding stroke are analyzed. Initially, it is noticed that patients who live far from metropolitan areas, and those who are limited by logistics, and social and financial resources, are more likely to have a worse prognosis and higher morbidity and mortality rates. ${ }^{26,27}$ Therefore, to make the identification of suspected stroke patients easier, it is suggested the use of a prehospital assessment tool in pre-hospital urgency and emergency services in Brazil and worldwide.

One of the limitations of this study is the absence of data about the clinical course of the patients, such 
as the diagnostic confirmation of the reviewed cases, prognosis, and outcome. These data would help to identify additional endpoints and other clinical demands.

Despite these limitations, this study allowed for characterization of the care provided in an area with limited medical, social, and financial resources, revealing failures, such as difficulty in early identification of stroke signs by family members, and deficient health care, in disagreement with guidelines' recommendations. Results obtained in this study are useful for developing socio-educational actions and health promotion programs, improving emergency response systems, qualifying health care professionals involved in these systems, and for implementing strategies that may contribute to a faster, more effective and more appropriate care. In addition, the fact that the study was conducted on an intentional, rather than a probabilistic sample probably limits inference of the findings to other populations.

\section{Conclusion}

This study revealed a low level of knowledge regarding the need to determine and register the exact time of symptom onset of suspected stroke patients. Also, the study highlighted the low rate of patients taken to the referral hospitals of the northern macro-region of Minas Gerais. These observations indicate the need for interventions, with health promotion programs, for defining a standardized referral system and providing continued training for health care professionals. Intervention measures, such as socioeducational campaigns in primary health care centers, as well as health promotion in stroke-related engaged fiction, have become critical to facilitate early detection and intervention for stroke. Further studies are required to evaluate the clinical and economic impact of emergency

\section{References}

1. Lotufo PA. Stroke in Brazil: a neglected disease. Sao Paulo Med J. 2005;123(1):3-4.

2. Kaste M. Every day is a world stroke day: act now, be a stroke champion and a torchbearer! Stroke. 2010;41(11):2449-50.

3. Centers for Disease Control and Prevention - CDC. Stroke Facts [database on the Internet]. 2017 [acesso em 25 Jun. 2019]. Disponível em: https:// www.cdc.gov/stroke/facts.htm.

4. Brito GV. Acidente vascular cerebral no Brasil: estimativa contemporânea do custo da doença no período hospitalar [trabalho de conclusão de curso]. Brasília: Universidade Federal de Goiás; 2017. services in areas where resources are scarce, as is the northern macro-region of Minas Gerais.

\section{Potential Conflict of Interest}

No potential conflict of interest relevant to this article was reported.

\section{Sources of Funding}

This study was funded by FINEP.

\section{Study Association}

This study is not associated with any thesis or dissertation work.

\section{Ethics approval and consent to participate}

This study was approved by the Ethics Committee of the Universidade Federal de Minas Gerais under the protocol number 065/11. All the procedures in this study were in accordance with the 1975 Helsinki Declaration, updated in 2013. Informed consent was obtained from all participants included in the study.

\section{Author contributions}

Conception and design of the research: Gusmão LL, Ribeiro TLP, Marcolino MS. Acquisition of data: Gusmão LL, Antunes I, Lopes U. Analysis and interpretation of the data: Gusmão LL, Nascimento IJB, Oliveira JAQ, Marcolino MS. Statistical analysis: Gusmão LL, Nascimento IJB, Oliveira JAQ. Obtaining financing: Ribeiro TLP, Marcolino MS. Writing of the manuscript: Gusmão LL, Nascimento IJB, Oliveira JAQ, Rocha GAS. Critical revision of the manuscript for intellectual content: Nascimento IJB, Antunes I, Fernandes BF, Sant'Anna RV, Oliveira JAQ, Lopes U, Ribeiro TLP, Marcolino MS.
5. Jauch EC, Cucchiara B, Adeoye O, Meurer W, Brice J, Chan YY, et al. Part 11: adult stroke: 2010 American Heart Association Guidelines for Cardiopulmonary Resuscitation and Emergency Cardiovascular Care. Circulation. 2010;122(18 Suppl 3):S818-28.

6. Brasil. Ministério da Saúde. Portaria n. 665, de 12 de abril de 2012. Diário Oficial da União 2012. [acesso em 20 Apr. 2020]. Disponível em : http:// bvsms.saude.gov.br/bvs/saudelegis/gm/2012/PRT0665_12_04_2012.html.

7. Brasil. Ministério da Saúde. Secretaria de Atenção à Saúde. Departamento de Atenção Especializada. Coordenação-Geral de Média e Alta Complexidade. 
8. Hospital Sírio Libanês. Protocolo gerenciado de Acidente Vascular Cerebral (AVC) [database on the Internet]; 2018. [acesso em 20 Apr. 2020]. Disponível em: https://www.hospitalsiriolibanes.org.br/institucional/gestao-daqualidade/Documents/2018-11-01-protocolos/Protocolo\%20Gerenciado\%20 de\%20Acidente\%20Vascular\%20Cerebral/Protocolo \%20AVC_VF.pdf.

9. Brasil. Ministério da Saúde. Departamento de Atenção Especializada, Coordenação Geral de Urgência e Emergência. Projeto Nacional de Atendimento à Doença Vascular Aguda. Brasília: OMS; 2008.

10. Tambara EM. Diretrizes para Atendimento Pré-Hospitalar no Acidente Vascular Cerebral;. Medicina Perioperatória. Rio de Janeiro: Sociedade de Anesteriologia do Estado do Rio de Janeiro; 2006. p. 77.

11. Smith WS, Corry MD, Fazackerley J, Isaacs SM. Improved paramedic sensitivity in identifying stroke victims in the prehospital setting. Prehosp Emerg Care. 1999;3(3):207-10.

12. Brasil. Ministério da Saúde. AVC: o que é, causas, sintomas, tratamentos, diagnóstico e prevenção; 2019. [acesso em 04 Set. 2020]. Disponível em: http://www.saude.gov.br/saude-de-a-z/acidente-vascular-cerebral-avc.

13. Instituto Brasileiro de Geografia e Estatística; 2010. [acesso em 20 Out. 2014]. Disponível em: http://www.ibge.gov.br/estadosat/perfil.php?sigla=mg.

14. Brasil. Ministério da Saúde. DATASUS. [acesso em 16 Set. 2014]. Disponível em: http://www2.datasus.gov.br/DATASUS/index.php.

15. Organização mundial da Saúde. Organização Pan-Americana da Saúde. Rede de Atenção à Urgência e Emergência na Macrorregião Norte de Minas Gerais: estudo de caso. Brasília: OMS; 2011.

16. Secretaria Municipal de Saúde de Franca SAMU. Protocolo Operacional Padrão. Franca - SP; 2012. 19 p.

17. Centers for Disease Control and Prevention. Glasgow Coma Scale. United States of America: Centers for Disease Control and Prevention; 2019. [acesso em 04 Abr. 2018]. Disponível em: https://www.cdc.gov/masstrauma/ resources/gcs.pdf.

18. Kothari RU, Pancioli A, Liu T, Brott T, Broderick J. Cincinnati prehospital stroke scale: reproducibility and validity. Ann Emerg Med. 1999;33(4):373-8.

19. Rede AVC Brasil. Hospitais da Rede Brasil AVC; 2020. [acesso em 04 Abr. 2015]. Disponível em: http://www.redebrasilavc.org.br/para-profissionaisde-saude/hospitais-rede-brasil-avc2/.
20. American Academy of Neurology. Few Stroke patients fet to hospital in time for treatment [database on the Internet]; 2006 [acesso em 25 Jun. 2019]. Disponível em: https://www.aan.com/PressRoom/Home/ PressRelease/334.

21. Ashraf VV, Maneesh M, PrAVCenkumar R, Saifudheen K, Girija AS Factors delaying hospital arrival of patients with acute stroke. Ann Indian Acad Neurol. 2015;18(2):162-6.

22. Meira F, Magalhães D, Silva LS, Mendonça e Silva AC, Silva GS Knowledge about stroke in Belo Horizonte, Brazil: a community-based study using an innovative video approach. Cerebrovasc Dis Extra. 2018;8(2):60-9.

23. Instituto de Pesquisa Econômica Aplicada. Programa das Nações Unidas para o desenvolvimento. Atlas de desenvolvimento humano do Brasil de 2013; 2013. [acesso em 25 Jun. 2019]. Disponível em: http://atlasbrasil. org.br/2013/.

24. Rede Urgência e Emergência CISRUN. Unidade da Rede AVC é inaugurada em Montes Claros; 2017 [acesso em 02 Set. 2019]. Disponível em: http://www.cisrun.saude.mg.gov.br/noticias/unidade-da-rede-avce-inaugurada-em-montesclaros/.

25. Breuer L, Schwab S. Telemedicine in stroke care. Med Klin Intensivmed Notfmed. 2017;112(8):687-94.

26. Joubert J, Prentice LF, Moulin T, Liaw ST, Joubert LB, Preux PM, et al Stroke in rural areas and small communities. Stroke. 2008;39(6):1920-8.

27. Howard G, Kleindorfer DO, Cushman M, Long DL, Jasne A, Judd SE, et al. Contributors to the excess stroke mortality in rural areas in the United States. Stroke. 2017;48(7):1773-8.

28. Acker 3rd JE, Pancioli AM, Crocco TJ, Eckstein MK, Jauch EC, Larrabee $\mathrm{H}$, et al. Implementation strategies for emergency medical services within stroke systems of care: a policy statement from the American Heart Association/American Stroke Association Expert Panel on Emergency Medical Services Systems and the Stroke Council. Stroke. 2007;38(11):3097-115

29. Rocha MS, Almeida AC, Abath Neto O, Porto MP, Brucki SM. Impact of stroke unit in a public hospital on length of hospitalization and rate of early mortality of ischemic stroke patients. Arq Neuro-Psiquiatr. 2013;71(10):774-9. 